\title{
Erratum to: Description of full-range strain hardening behavior of steels
}

Tao Li ${ }^{1}$, Jinyang Zheng ${ }^{1,3,4^{*}}$ and Zhiwei Chen ${ }^{2}$

\section{Erratum to: SpringerPlus (2016) 5:1316 DOI 10.1186/s40064-016-2998-3}

Following the publication of our article ( $\mathrm{Li}$ et al. 2016), we have become aware that the legends of Fig. 2 and Table 2 should read as follows:

Fig. 2 Measured stress-strain curves of the steels. a Gun steels. b Other steels. b is adapted from Figure 10 in International Journal of Nonlinear Mechanics, Vol 46(3), Hertelé S, De Waele W, Denys R, A generic stress-strain model for metallic materials with two-stage strain hardening behaviour, pp 519-531, Copyright (2010) with permission of Elsevier (Hertelé et al. 2011).

Table 2 Fitting parameters of other formulas. Data for pipeline steel, TRIP steel and stainless steel are from Table 3 in International Journal of Nonlinear Mechanics, Vol 46(3), Hertelé S, De Waele W, Denys R, A generic stress-strain model for metallic materials with twostage strain hardening behaviour, pp 519-531, Copyright (2010) adapted with permission of Elsevier (Hertelé et al. 2011).

\begin{abstract}
Author details
${ }^{1}$ Institute of Process Equipment, Zhejiang University, Hangzhou 310027, Zhejiang, People's Republic of China. ${ }^{2}$ Chinese Standardization Committee on Boilers and Pressure Vessels, Beijing 100029, People's Republic of China. ${ }^{3}$ High-Pressure Process Equipment and Safety Engineering Research Center of Ministry of Education, Zhejiang University, Hangzhou 310027, Zhejiang, People's Republic of China. ${ }^{4}$ The State Key Laboratory of Fluid Power Transmission and Control, Zhejiang University, Hangzhou 310027, Zhejiang, People's Republic of China.
\end{abstract}

The online version of the original article can be found under doi:10.1186/s40064-016-2998-3.

Received: 6 December 2016 Accepted: 6 December 2016 Published online: 22 December 2016

\author{
Reference \\ Li T, Zheng J, Chen Z (2016) Description of full-range strain hardening behavior \\ of steels. SpringerPlus 5:1316
}

\footnotetext{
*Correspondence: jyzh@zju.edu.cn

${ }^{1}$ Institute of Process Equipment, Zhejiang University, Hangzhou 310027,

Zhejiang, People's Republic of China

Full list of author information is available at the end of the article
} provided you give appropriate credit to the original author(s) and the source, provide a link to the Creative Commons license, and indicate if changes were made. 